\title{
Identification of the exo loci required for exopolysaccharide synthesis in Agrobacterium radiobacter NCIB 11883
}

\author{
E. L. H. Aird, G. Brightwell, M. A. Jones and A. W. B. Johnston* \\ School of Biological Sciences, University of East Anglia, Norwich NR4 7TJ, UK
}

(Received 13 May 1991; revised 25 June 1991; accepted 8 July 1991)

\begin{abstract}
We initiated a genetic analysis of Agrobacterium radiobacter NCIB 11883 with particular reference to the (exo) genes required for exopolysaccharide synthesis. Following mutagenesis with nitrosoguanidine, several exo mutant strains were isolated and several of the mutations were corrected by DNA cloned in a newly constructed cosmid library. Analysis of various complementing cosmids by genetic and physical criteria indicated that exo loci were quite widely dispersed in the bacterial genome. Certain exo mutations were corrected by different cosmids that shared no homologous DNA; possible explanations for this are presented. Using phoA fusions, it was shown that some exo genes were, or were closely linked to, genes that specified polypeptides associated with the bacterial cell surface. By introducing the cloned exo genes of Rhizobium meliloti it was found that only one out of thirty exo mutants of $A$. radiobacter was corrected by a defined exo locus of the former species; further analysis indicated that this particular exo gene corresponded to exoB of $R$. meliloti. Finally, it was found that several $A$. radiobacter exo mutants were non-mucoid on media with dicarboxylic acids as sole carbon source but appeared to be wild-type when sugars were the source of carbon.
\end{abstract}

\section{Introduction}

Members of the genera Agrobacterium and Rhizobium share several features. Both interact with higher plants; Rhizobium species form nitrogen-fixing root nodules in association with legumes, whereas Agrobacterium species induce crown gall tumours or hairy roots on a range of dicotyledonous plants.

Agrobacterium is closely related to Rhizobium meliloti as judged by sequence comparison of the 16S RNA. Both these bacteria make various extracellular polysaccharides that are important for their interactions with their host plants. Thus, both $R$. meliloti and Agrobacterium tumefaciens make an extracellular polysaccharide cyclic $1,2-\beta$-D-glucan, that is required for normal nodule formation and the induction of crown galls respectively. In $R$. meliloti, two genes, $n d v A$ and $n d v B$ are required for the manufacture and export of this glucan (Geremia et al., 1987) and in $A$. tumefaciens chvA and $c h v B$ are responsible for its synthesis and export, respectively. These two sets of genes ( $n d v$ and chv) are in both cases chromosomal and are homologous and functionally equivalent; the defects of $c h v$ mutants can be corrected

Abbreviations: AMP, 2-amino-2-methyl-1-propanol; CAPSO, 3(cyclohexylamino)-2-hydroxy-1-propanesulphonic acid; EPS, acidic exopolysaccharide; XP, 5-bromo-4-chloro-3-indolyl phosphate. by cloned $n d v$ genes and vice versa (Dylan et al., 1986). In addition, the major high-molecular-mass acidic exopolysaccharide (EPS) produced by both genera is a succinoglycan, which consists of repeating units of $\beta$-linked glucose and galactose $(7: 1)$ with acidic side groups (Hisamatsu et al., 1980; Sutherland, 1985). Mutants of $R$. meliloti which fail to make this polymer induce aberrant, non-fixing nodules which are devoid of bacteria (see for example Finan et al., 1986; Leigh et al., 1986).

There has been considerable interest in the exo genes of $R$. meliloti, which are needed for EPS synthesis. Several exo loci (exoP, exo $N$, exoM, exo $A$, exoL, exoK, exoH, exoJ, exoG, exo $F$, exo $Q$ and exoB) have been located in a cluster on a large indigenous plasmid and two other loci, exoC and exoD, are on the chromosome (Long et al., 1988 $b$; Finan et al., 1986). In addition there are two unlinked chromosomal loci, exoR and exoS, whose products negatively regulate the synthesis of EPS (Doherty et al., 1988). The biochemical function of two of the exo genes has been established: exoB appears to encode a UDP-galactose-4-epimerase (Buendia et al., 1991) and sequence analysis of exoB revealed that its product is similar ( $39 \%$ identity) to the epimerase encoded by the galE gene of Escherichia coli.

In Agrobacterium, studies on exo genes have been less detailed than in Rhizobium. Cangelosi et al. (1987) 
isolated several exo mutant strains of $\boldsymbol{A}$. tumefaciens and isolated recombinant plasmids from a clone bank of genomic DNA which could correct them. Interestingly, more than $75 \%$ of these exo mutants could be corrected by cloned exo loci of $R$. meliloti. However, some mutants, in a locus termed exoG, failed to be corrected by any known exo gene of $R$. meliloti (Cangelosi et al., 1987). Of the exo mutants of $A$. tumefaciens, only those in the exoC locus were defective in tumorigenesis. Significantly, the exoC mutants were pleiotropically defective; they were also unable to make cyclic $1,2-\beta$-D-glucan and it was proposed that it was this that abolished tumour formation rather than the production of the acidic exopolysaccharide per se. Further, it has been shown that the inability of exoC mutants to synthesize $1,2-\beta$-Dglucan and succinoglycan is due to a deficiency in the activity of the enzyme phosphoglucomutase which in wild-type bacteria converts glucose 6-phosphate to glucose 1-phosphate, an intermediate in the synthesis of UDP-glucose (Uttaro et al., 1990).

The products of several exo genes appear to be associated with the bacterial membrane or periplasm (Long et al., 1988b, Latchford et al., 1991). This was deduced following the construction of fusions between exo genes and a defective form of phoA, the gene that specifies alkaline phosphatase (Manoil \& Beckwith, 1985). This pho $A$ lacks a promoter, ribosome binding site and the leader sequence that is responsible for the targeting of the enzyme to the periplasm. Since the enzyme is only active in the periplasm, this defective pho $A$ can only express alkaline phosphatase if it is fused, in-frame, to a gene whose product is normally located in the periplasm or is inserted into the bacterial membrane such that at least part of the AP fusion is located in the periplasm.

In this study we report the isolation of mutants of $A$. radiobacter strain NCIB 11883 which are defective in the production of EPS and the molecular cloning and characterization of some of the exo genes in this strain.

\section{Methods}

Bacterial strains, plasmids, media and growth conditions. The strains used are presented in Table 1, together with the plasmids that were employed and constructed in this study. Escherichia coli strains were cultured on LB medium (Maniatis et al., 1982) at $37^{\circ} \mathrm{C}$. Rhizobium leguminosarum strain 8401 was grown on TY medium (Beringer, 1974) at $28^{\circ} \mathrm{C}$. A radiobacter was grown at $28^{\circ} \mathrm{C}$ on either $\mathrm{LB}$ or TY medium or minimal medium MOD-D2, $\mathrm{pH} 7 \cdot 0$, containing ( $\left.\mathrm{g} \mathrm{l}^{-1}\right): \mathrm{KH}_{2} \mathrm{PO}_{4}$, $3.0 ; \quad \mathrm{Na}_{2} \mathrm{HPO}_{4}, \quad 3.0 ; \quad\left(\mathrm{NH}_{4}\right)_{2} \mathrm{SO}_{4}, \quad 0.3 ; \quad \mathrm{MgSO}_{4} .7 \mathrm{H}_{2} \mathrm{O}, \quad 0.2 ;$ $\mathrm{CaCl}_{2} .2 \mathrm{H}_{2} \mathrm{O}, 0.015 ; \mathrm{FeCl}_{3}, 0.067$; plus trace elements; $1 \mathrm{ml}$ from a stock solution containing $\left(\mathrm{g} \mathrm{l}^{-1}\right) ; \mathrm{CaCl}_{2} .6 \mathrm{H}_{2} \mathrm{O}, 0.66 ; \mathrm{ZnSO}_{4}, 0.18$; $\mathrm{CuSO}_{4}, \quad 0.16 ; \mathrm{MnSO}_{4}, 0.15 ; \quad \mathrm{CoCl}_{2}, 0.18 ; \mathrm{H}_{3} \mathrm{BO}_{3}, \quad 0 \cdot 10 ;$ $\mathrm{Na}_{2} \mathrm{MoO}_{4} \cdot 2 \mathrm{H}_{2} \mathrm{O}, 0 \cdot 30$. MOD-D2 was supplemented with D-glucose $\left(5 \mathrm{~g}^{-1}\right)$, glycerol $\left(5 \mathrm{~g} \mathrm{l}^{-1}\right)$ or sodium succinate $\left(5 \mathrm{~g} \mathrm{l}^{-1}\right)$ as sole $\mathrm{C}$ source as indicated.
Genetic manipulations. pLAFR1-based plasmids were transferred into $A$. radiobacter strain T1305 (a derivative of NCIB 11883) in triparental crosses in which E. coli containing the plasmid pRK2013 was used as the helper strain (Figurski \& Helinski 1979). Selection for transfer of the recombinant plasmids was done by plating on medium containing streptomycin at $200 \mu \mathrm{g} \mathrm{ml}^{-1}$ (to which T1305 is resistant) plus tetracycline at $2-5 \mu \mathrm{g} \mathrm{ml}^{-1}$ (against which pLAFR1 confers resistance).

Cells of $A$. radiobacter were mutagenized with nitrosoguanidine (NTG) as follows. Approximately $10^{8}$ cells were spread on a Petri dish of TY medium and, following incubation at $28^{\circ} \mathrm{C}$ for $8 \mathrm{~h}$, some solid NTG was deposited in the centre of the plate. After $2 \mathrm{~d}$ incubation there was a zone of clearing around the NTG; with a sterile loop, bacteria were harvested from the edge of this zone of clearing, suspended in $20 \%(\mathrm{v} / \mathrm{v})$ glycerol and then plated on various media following appropriate dilutions.

Transposon mutagenesis. (a) Tnslac (Simon et al., 1989). E. coli strain A118 contains a chromosomally located copy of Tn 5 lac (A. Economou, unpublished). Plasmids pBIO11 and pBIO21 (see Results) were introduced into strain $\mathrm{A} 118$ by transformation and the derivatives were used as donors in triparental crosses with the polA Nal ${ }^{r} E$. coli strain C2110 as recipient (the mobilizing plasmid pRK2013 does not survive in this strain). Selection was made on media containing nalidixic acid, kanamycin and tetracycline $\left(50,20\right.$ and $5 \mu \mathrm{g} \mathrm{ml}^{-1}$ respectively). Thus derivatives of these two plasmids containing random insertions of the transposon were isolated. Initially, a collection of TnSlac insertions into each plasmid was mobilized en masse from $E$. coli $\mathrm{C} 2110$ to one or more of the $A$. radiobacter exo mutants that was corrected by $\mathrm{pBIO} 11$ and/or pBIO21. Several non-mucoid transconjugants were obtained, suggesting that they contained mutant plasmids with the transposon in the appropriate exo gene. However, despite repeated attempts, using different methods, it proved impossible to transform $E$. coli using preparations from these non-mucoid bacteria. Therefore, colonies of C2110(pBIO11::Tn5lac) or C2110(pBIO21::Tn5lac) were gridded out and the various mutant plasmids were mobilized into appropriate exo mutant strains and into wild-type $A$. radiobacter. In the latter case, attempts were made to introduce the insertions into the genome by marker exchange (Ruvkun \& Ausubel 1981).

(b) TnphoA (Manoil \& Beckwith, 1985). Plasmids pBIO11 or pBIO21 were introduced into $E$. coli strain $\mathrm{A} 143$, which contains a chromosomal copy of TnphoA (A. Economou, unpublished). R. leguminosarum strain 8401 was used as a recipient in triparental crosses with these $E$. coli strains, selection being for $\mathrm{Kan}^{\mathrm{r}}$ (TnphoA), $\operatorname{Tet}^{\mathrm{r}}$ (pLAFR1), $\operatorname{Str}^{\mathrm{r}}$ (8401) transconjugants. The reasons for this choice of recipient were (1) that we thought TnphoA insertions might be rare and (2) the difficulty see above - of getting recombinant plasmids out of strain T1305. We felt that the behaviour of any fusions would be similar in Rhizobium and in the closely related $A$. radiobacter, although of course this could not be guaranteed. Thus derivatives of $\mathrm{pBIO} 11$ and PBIO21 containing TnphoA were isolated. Colonies were replicated to medium containing 5-bromo-4-chloro-3-indolyl phosphate (XP; $40 \mu \mathrm{g} \mathrm{ml}^{-1}$ ). From those colonies that were blue, plasmid DNA was isolated (Hombrecher $e t$ al., 1984 ) and the plasmids were introduced into $E$. coli by transformation.

DNA manipulations. Transformation of $E$. coli, digestion of DNA with restriction endonucleases and ligations were done essentially as described by Maniatis et al. (1982). Plasmid DNA was isolated from $E$. coli as described by Holmes \& Quigley (1981) or according to the protocol recommended by Hybaid with their Qiagen kit.

Plasmid DNA was isolated from Rhizobium and A. radiobacter as described by Grosveld $e t$ al. (1981) for $E$. coli and modified for these bacteria as described by Hombrecher et al. (1984).

A cosmid clone bank of $\boldsymbol{A}$. radiobacter was constructed by isolating genomic DNA then, following partial digestion with EcoRI and sizefractionation on an $\mathrm{NaCl}$ gradient, ligating fragments $25-30 \mathrm{~kb}$ in size 
Table 1. Bacterial strains and plamids

\begin{tabular}{|c|c|c|}
\hline Strain or plasmid & Relevant properties & References \\
\hline \multicolumn{3}{|l|}{ A. radiobacter } \\
\hline NCIB 11883 & Field isolate, produces large amounts of succinoglycan EPS & Linton et al. (1987) \\
\hline $\begin{array}{l}\text { T1305 } \\
\text { Exo? }\end{array}$ & Derivative of NCIB $11883 ; \mathrm{Str}^{\mathrm{r}}$ & J. D. Linton (unpublished) \\
\hline \multicolumn{3}{|l|}{$\begin{array}{l}\text { Exo } 7 \\
\text { Exo } 51.1\end{array}$} \\
\hline Exo 53.1 & \multirow{2}{*}{\multicolumn{2}{|c|}{ EPS- derivatives of T1305 }} \\
\hline Exo 53.2 & & \\
\hline Exo 61.1 & & \\
\hline Exo 63 & \multicolumn{2}{|l|}{ 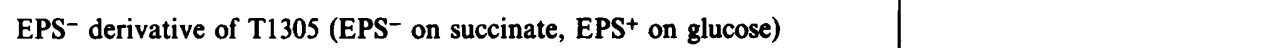 } \\
\hline Exo 64 & \multicolumn{2}{|l|}{ EPS $^{-}$derivative of $\mathrm{T} 1305$} \\
\hline Exo 65.2 & \multicolumn{2}{|l|}{ EPS- derivative of $\mathrm{T} 1305$} \\
\hline Exo 66.1 & \multicolumn{2}{|l|}{ EPS- derivative of T1305 (EPS ${ }^{-}$on succinate, EPS ${ }^{+}$on glucose) } \\
\hline Exo 66.3 & \multirow{2}{*}{\multicolumn{2}{|c|}{$\begin{array}{l}\text { EPS- derivative of T1305 } \\
\text { EPS- derivative of T1305 }\end{array}$}} \\
\hline Exo 70.1 & & \\
\hline Exo 73.1 & \multicolumn{2}{|l|}{ EPS- derivative of $\mathrm{T}^{-} 305$ (EPS- $^{-}$on succinate, $\mathrm{EPS}^{+}$on glucose) } \\
\hline Exo 73.2 & \multicolumn{2}{|l|}{ EPS- derivative of T1305 (EPS- on succinate, EPS ${ }^{+}$on glucose) } \\
\hline Exo 74 & \multirow{3}{*}{\multicolumn{2}{|c|}{ EPS $^{-}$derivative of T1305 (EPS ${ }^{-}$on succinate, EPS ${ }^{+}$on glucose) }} \\
\hline Exo 81 & & \\
\hline Exo 82 & & \\
\hline Exo 84.1 & \multirow{2}{*}{\multicolumn{2}{|c|}{ EPS- derivatives of T1305 }} \\
\hline Exo 84.2 & & \\
\hline \multirow{2}{*}{\multicolumn{3}{|c|}{$\begin{array}{l}\text { Exo } 85 \\
\text { Exo } 87.1\end{array}$}} \\
\hline & & \\
\hline \multicolumn{3}{|l|}{ Exo 87.2} \\
\hline SGN-1 & T1305::Tn5, EPS- derivative of T1305 & J. D. Linton (unpublished) \\
\hline R. leguminosarum & A derivative of strain 8002 cured of the symbioytic plasmid pRP2JI, Str & Lamb et al. (1982) \\
\hline \multicolumn{3}{|l|}{ E. coli } \\
\hline & Met $^{-}$; used as a recipient in routine transformations & Wood (1966) \\
\hline $\mathrm{C} 2110$ & $\mathrm{Nal}^{r} \mathrm{PolA}^{-}$ & Stachel et al. (1985) \\
\hline $\mathrm{CC} 118$ & \multirow{2}{*}{$\begin{array}{l}\text { Lac ; used for routine transiormations } \\
\text { CC118::Tn5lac; Kan }\end{array}$} & Manoil \& Beckwith (1985) \\
\hline Al18 & & A. Economou (unpublished) \\
\hline A143 & $\mathrm{C} 2110::$ TnphoA; Nal, $\mathrm{Kan}^{\mathrm{r}}$ & A. Economou (unpubilsned) \\
\hline \multicolumn{3}{|l|}{ Plasmids } \\
\hline pRK2013 & \multirow{4}{*}{$\begin{array}{l}\text { Used for mobilizing Pl-group plasmids, } \mathbf{K a n}^{\mathrm{r}} \\
\text { P-group plasmid used for marker exchange; Gent }{ }^{\mathrm{r}}, \mathrm{Spc}^{\mathrm{r}}, \mathrm{Str}^{\mathrm{r}} \\
\text { Wide-host-range P-group cloning vector; Tet } \\
\text { Wide-host-range P-group cloning vector; Tet }{ }^{\mathrm{r}} \text {, lacZ }\end{array}$} & Figurski \& Helinski (1979) \\
\hline pPHIJI & & Beringer et al. (1978) \\
\hline pLAFR1 & & Friedman et al. (1982) \\
\hline pMP220 & & Spaink et al. (1987) \\
\hline \multicolumn{3}{|c|}{$\begin{array}{l}\text { Recombinant plasmids } \\
\text { pD34 } \quad R \text {. meliloti DNA containing exoP, } N, M, A, L, K \text {, and } H \text { cloned in }\end{array}$} \\
\hline pD34 & \multirow{5}{*}{$\begin{array}{l}\text { R. meliloti DNA containing exoP, } N, M, A, L, K \text {, and } H \text { cloned in } \\
\text { pLAFR } 1 \text {; Tet } \\
R \text {. meliloti DNA containing exoJ, } G, F, Q \text {, and } B \text { cloned in pLAFR } 1 \text {; Tet }{ }^{r} \\
R \text {. meliloti DNA containing exoC cloned in pLAFR } 1 ; \text { Tet }^{\mathrm{r}} \\
R \text {. meliloti DNA containing exoP, } N, M, A, L, K, H, J, G, F, Q \text { cloned in } \\
\text { pLAFR } 1\end{array}$} & Long et al $(1088 h)$ \\
\hline pD56 & & \\
\hline pD15 & & Leigh et al. (1986) \\
\hline $\mathrm{pEX} 312$ & & \\
\hline & & Long et al. $(1988 b)$ \\
\hline
\end{tabular}

to EcoRI-cut pLAFR1 DNA (Downie et al., 1983). Following packaging into $\lambda$ phage packaging mix (Stratagene), approximately 10000 Tet $^{r}$ transfectants were obtained.

For hybridization experiments, genomic or plasmid DNA was transferred to a Hybond-N filter (Maniatis et al., 1982) and was probed with digoxygenin-labelled DNA probes according to the manufacturer's (Boehringer) instructions.

\section{Results}

\section{Isolation of Exo- mutants of $A$. radiobacter}

Following mutagenesis of $A$. radiobacter strain T1305 with NTG, approximately 2000 survivors were plated on
MOD-D2 medium containing one of L-glycerol, Dglucose or sodium succinate as sole $\mathrm{C}$ source. After $3 \mathrm{~d}$ incubation at $28{ }^{\circ} \mathrm{C}$ the colonies were inspected and any that were less mucoid than the wild type were purified and retained for further study.

Completely non-mucoid colonies occurred at a frequency of approximately $1 \%$ on each of the media. In addition to the completely non-mucoid mutants, other colonies were seen that were semi-mucoid or which had an altered 'wrinkled' appearance, indicating that they too were in some way affected in EPS production. However, these 'leaky' mutants were not studied further. 
Some Exo mutants are EPS- on media containing succinate but are $\mathrm{EPS}^{+}$on medium containing glucose or glycerol

Following purification of the EPS- mutants from the three different media they were each examined on media containing glycerol, glucose or succinate. All those that were EPS- on the glucose or glycerol media were also non-mucoid on all three media. However, five of the mutants (Exo 63, 73.1, 73.2, 66.1 and 74) that were EPS $^{-}$on medium containing succinate as sole $\mathrm{C}$ source were fully mucoid and had an apparently wild-type phenotype on media containing glycerol or glucose as carbon source. These five strains were then plated on MOD-D2 supplemented with one of several carbon sources. All of these mutants were fully mucoid on media containing glucose, galactose, ribose, fructose, maltose, citrate or pyruvate, but on media in which the dicarboxylic acids fumarate or succinate were the sole C source, the colonies appeared to be completely EPS ${ }^{-}$.

When $A$. radiobacter strains were grown on minimal medium ( $\mathrm{pH} 7.0)$ containing glucose and a universal indicator (BDH) the $\mathrm{pH}$ was found to drop to around 6.5 after 4-5 d growth. However, if succinate was used as the $\mathrm{C}$ source the $\mathrm{pH}$ rose from 7 to 9 during the same period of time. The wild-type strain of $A$. radiobacter is slightly less mucoid on medium containing succinate as a $\mathrm{C}$ source than when glucose is added. To establish whether the 'Suc' $\mathrm{Glu}^{+}$' strains are EPS' as a result of the high $\mathrm{pH}$ on medium containing succinate, Exo 73.1 and the wild-type strain T1305 were grown on MOD-D2 medium supplemented with succinate and 50 or 100 mM-HEPES ( $\mathrm{pH} 7$ ) for $2-3 \mathrm{~d}$. The presence of 50 or 100 mM-HEPES maintained a $\mathrm{pH}$ of around 7 in cultures supplemented with succinate but EPS production was not improved and growth was unaffected. Conversely, maintaining a $\mathrm{pH}$ of 9 in media buffered with $10 \mathrm{~mm}$-CAPSO or AMP and supplemented with glucose as $C$ source did not reduce EPS production in the wild-type or strain Exo 73.1. Therefore we conclude that the conditional phenotype of this mutant is not due to differences in $\mathrm{pH}$.

\section{Identification of recombinant plasmids that correct exo mutants of $A$. radiobacter.}

Fragments of EcoRI-digested $A$. radiobacter DNA approximately $30 \mathrm{~kb}$ in size were ligated to PLAFR 1 and packaged into bacteriophage $\lambda$. Approximately 10000 primary transfectants were obtained. Given the size of the bacterial genome and the size of the cloned inserts, this number is certainly sufficient to represent the entire genome in the clone bank.

To identify recombinant plasmids which corrected exo mutants, the recombinant plasmids were mobilized en masse in triparental matings into representative exo mutants of $A$. radiobacter. Approximately 1000 transconjugants for each recipient were plated on MOD-D2 medium containing the $\mathrm{C}$ source on which the mutants were initially identified. These colonies were inspected for any that were mucoid, indicating that the exo mutation had been corrected by a recombinant plasmid. For approximately half of the recipient strains at least one colony was mucoid; for the remaining exo mutants which failed to be corrected it is likely that this may be due simply to statistical sampling since approximately 1000 recombinant plasmids is only just sufficient to give a $90 \%$ probability of isolating a given gene.

Plasmid DNA was isolated from the mucoid colonies and was introduced into $E$. coli by transformation, selecting for tetracycline resistance. The recombinant plasmids were then re-introduced by conjugation from $E$. coli into the $A$. radiobacter strain in which their effect on EPS production had initially been detected. In most cases, as expected, the appropriate exo mutant recipient was uniformly corrected by the reintroduced plasmid; where this was not the case, it is possible that the original mucoid colonies were due to reversion of the exo mutation, or, perhaps the recombinant plasmid had undergone some rearrangement during the course of its isolation or transformation. In any event, these plasmids were not examined further.

\section{exo genes are located in at least five different regions of the genome}

To determine if any of the plasmids that contained exo genes shared the same cloned DNA, representative plasmids were labelled with digoxygenin and used as probes to DNA from each of the other plasmids which had been digested with EcoRI, run on an agarose gel and transferred to a nylon membrane (Southern, 1975). As judged by the sizes of restriction fragments in different plasmids, together with the patterns of hybridizing fragments, it was clear that the eleven plasmids that were studied fell into five groups in which the cloned DNA of one group did not hybridize with that of any of the others. Three of the groups contained more than one, non-identical plasmids which had two or more EcoRI fragments in common.

As shown in Fig. 1, the plasmids in group 1 (pBIO15, $\mathrm{pBIO} 16$ and $\mathrm{pBIO} 17$ ) shared a total of $18 \mathrm{~kb}$ and those in group 3 (pBIO12 and pBIO24) have $10 \mathrm{~kb}$ (two fragments) in common. The five plasmids (pBIO2, pBIO10, $\mathrm{pBIO} 13, \mathrm{pBIO} 14$ and $\mathrm{pBIO} 21$ ) in group 2 all shared two fragments comprising $12.1 \mathrm{~kb}$. Note that in this group, pBIO2 also contained an EcoRI fragment that did not 'fit' - it seems likely that this was due to the addition of a piece of non-contiguous DNA during the cloning steps. 


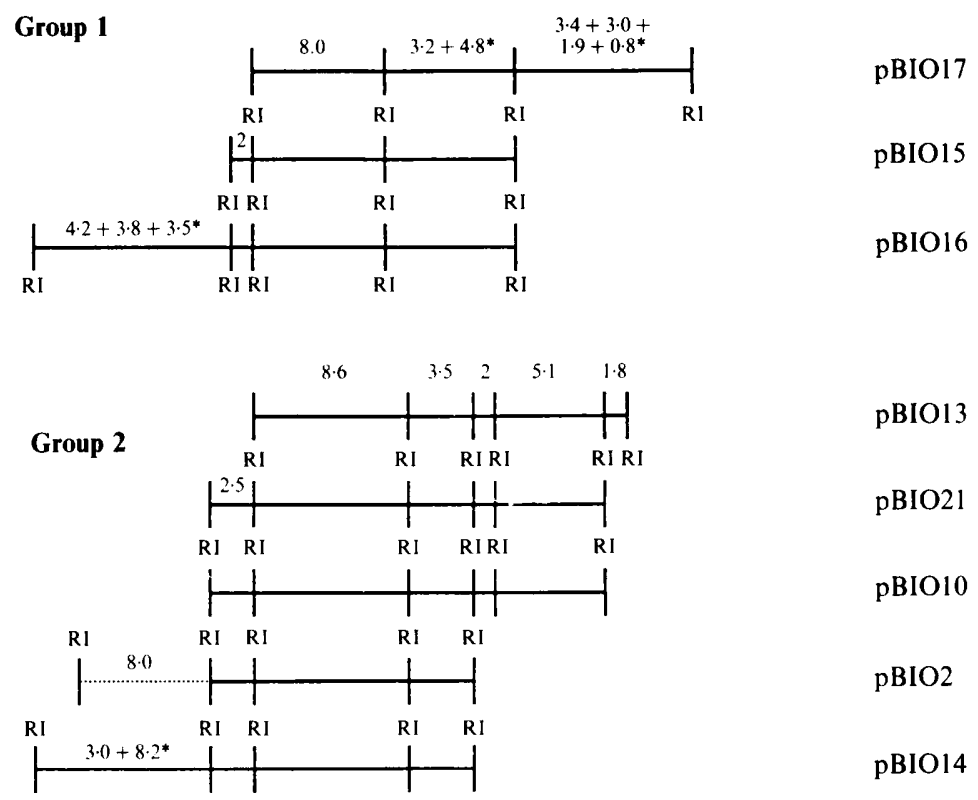

Group 3

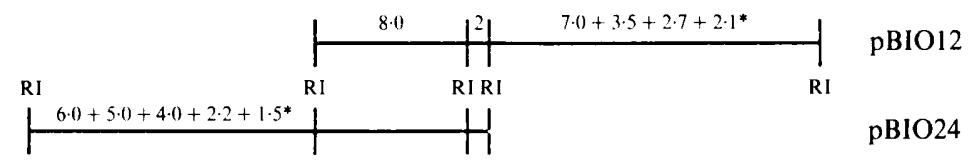

Group $4 \quad$ No maps available

pBIO25

Fig. 1. Restriction maps of recombinant plasmids containing cloned exo genes. Plasmids are arranged in groups; those in the same group share cloned DNA as judged by hybridization studies. RI, EcoRI sites. An asterisk indicates contiguous fragments that have not been ordered. The dotted line in pBIO2 refers to a fragment that probably came from elsewhere in the

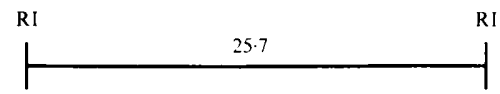

pBIO11 genome. The numbers refer to the sizes of fragments (kb).

Table 2. exo alleles corrected by $A$. radiobacter recombinant plasmids

\begin{aligned} & \hline \hline \multicolumn{1}{l}{ Plasmids } \multicolumn{1}{c}{ exo alleles corrected } \\ & \hline Group 1 pBIO17 $87.1,87.2,7 \\ &$ pBIO15 $87.1,87.2,7 \\ &$ pBIO16 $87.1,87.2,7 \\ &$ Group 2 pBIO13 $81,82,66.1^{*}, 70.1,51.1,73.2^{*}, 66.3,53.1 \\ & 61.1 \\ &$, pBIO21 $81,82,66.1^{*}, 70.1,51.1,73.2^{*}, 66.3,53.1 \\ &, 61.1,65.2,73.1^{*}, 53.2,63^{*}, 74^{*} \\ &$ pBIO10 $81,82,66.1^{*}, 70.1,51.1,73.2^{*}, 66.3,53.1 \\ &, 61.165 .2,73.1^{*}, 53.2,63^{*}, 74^{*} \\ &$ pBIO2 $81,82,66.1^{*}, 70.1,51.1,73.2^{*}, 66.3,53.1 \\ &, 61.165 .2,73.1^{*}, 53.2,63^{*}, 74^{*} \\ &$ pBIO14 $81,82,66.1^{*}, 70.1,51.1,73.2^{*}, 66.3,53.1 \\ &, 61.165 .2,73.1^{*}, 53.2,63^{*}, 74^{*} \\ &$ Group 3 pBIO12 $84.1,84.2 \\ &$ pBIO24 $84.1,84.2,85 \\ &$ Group 4 pBIO25 SGN-1 \\ & Group 5 pBIO11 $81,82,66.1^{*}, 51.1,53.1,65.2,53.2,63^{*} \\ &$\hline \hline\end{aligned}

* indicates exo strains which were $\mathrm{EPS}^{-}$on medium containing succinate but $\mathrm{EPS}^{+}$on glucose.

Two other plasmids, pBIO11 and pBIO25 each contained approximately $30 \mathrm{~kb}$ of cloned DNA which, as judged by the hybridization experiments, did not overlap with each other nor with any of the plasmids named above.

The incomplete EcoRI restriction maps of these 5 'contigs' are shown in Fig. 1 and the exo alleles that they correct are listed in Table 2.

\section{Genetic characterization of the plasmids containing exo genes}

Each of the plasmids identified above, in addition to being transferred into the exo mutant which they had initially been found to correct, was also mobilized separately into all of the exo mutants that had been isolated. To a large extent, the results were consistent with the physical classification of the plasmids in that plasmids in the same group tended to correct the same sets of exo alleles. Thus pBIO15, pBIO16 and pBIO17 (group 1) all corrected exo7, exo87.1 and 87.2, pBIO12 
and pBIO24 corrected exo84. 1 and exo84 2 and pBIO24 also corrected exo85. pBIO25, which did not overlap with any of the other cosmids, only corrected the EPSstrain SGN-1, the strain which had initially been used to detect it.

For the group 2 plasmids the patterns were more complex (Fig. 1, Table 2). Three alleles, exo73.2, exo81 and exo82, were fully corrected by all five plasmids and six others, exo51.1, exo53.1, exo70.1, exo61.1, exo66.3 and exo66. 1 were partially corrected by all the plasmids; in those that were partially corrected the transconjugants had an appearance intermediate between the wild-type and the original mutant. A further five alleles, exo53.2, exo65.2, exo63, exo73.1 and exo74, were corrected by four of the plasmids (pBIO21, pBIO10, pBIO2 and pBIO14) suggesting that the above four alleles are in or near the DNA common to these plasmids but absent from pBIO13 which failed to correct these alleles. As indicated in Fig. 1 and Table 2, the correction pattern of a few alleles was not readily reconcilable with the maps of the overlapping plasmids. One possibility is that those alleles may in fact not be single point mutations; in this connection, it is relevant to note that the mutagen used, NTG, is known to induce multiple mutations at the region of the DNA replication fork.

As indicated in Table 2, several of the mutants that were $\mathrm{EPS}^{-}$on succinate media but $\mathrm{EPS}^{+}$on glucose media were corrected by members of the group 2 plasmids. Thus these $\mathrm{C}$-source-dependent exo mutations are closely linked to several 'unconditional' exo alleles.

\section{Correction of some exo alleles by different DNA sequences}

The mutant containing the exo82 allele was the one that had been initially used to isolate pBIO11. It was surprising therefore to find that this mutation was also corrected by all the plasmids in group 2 ; as described above, these plasmids have completely different restriction patterns from pBIOll and, as judged by the hybridizations, contain no homologous DNA. Further, pBIOl1 was found to correct several of the exo mutants that had originally been used to obtain members of the group 2 plasmids (Table 2). Some, but not all, of the $\mathrm{C}$ source-dependent mutants were corrected by pBIO11 but there was no clear pattern relating those alleles that were corrected by $\mathrm{pBIO} 11$ to those that were corrected only by the other group 2 plasmids.

The group 2 region (represented by $\mathrm{pBIO} 21$ ) and pBIO11 were studied in more detail $(a)$ because of the apparently paradoxical ability of different regions of DNA to correct the same alleles and $(b)$ because each could complement the novel $\mathrm{C}$-source-dependent exo mutants.

\section{Subcloning of exo DNA from $p B I O 11$ and pBIO21}

(i) pBIO11. By a combination of single and double digests a restriction map of pBIO11 was established (Fig $2 a$ ). One feature of the cloned DNA was that it appeared to be under-represented in restriction sites. For example the only EcoRI sites were at the site of ligation to the vector, the insert DNA being a single $30 \mathrm{~kb}$ EcoRI fragment. Also the cloned DNA contained no BamHI or SacI sites. The significance of this paucity of certain restriction sites is not clear.

Following digestion of pBIO11, six SphI fragments were obtained. Each was individually cloned into pMP220 and the resultant plasmids were individually mobilized into each of the exo mutants that were corrected by pBIO11. One of these plasmids, pBIO343 (Fig $2 a$ ), containing an $11.8 \mathrm{~kb} S p h \mathrm{I}$ fragment, corrected all the mutants. A $4 \mathrm{~kb}$ HindIII fragment from pBIO343 was further subcloned into pMP220 to form pBIO344. Again, the resultant plasmid corrected all the exo mutants that were complemented by pBIO11. (Note that, as shown in Fig. $2 a$, the 'right hand' HindIII site was derived from the linker in pBIO344.)

(ii) pBIO21. A preliminary restriction map of $\mathrm{pBIO} 21$ is shown in Fig. 1 and a more extensive one is in Fig. 2(b). By subcloning various fragments of the insert DNA from pBIO21, it was found that a $4 \mathrm{~kb}$ EcoRI-BamHI fragment, cloned into pMP220 to form pBIO60, was sufficient to restore EPS synthesis to all of the exo mutants that were corrected by pBIO21 itself.

Thus the exo regions in $\mathrm{pBIO} 11$ and $\mathrm{pBIO} 21$ were located in two fairly small segments of DNA in the two plasmids.

\section{Mutagenesis of pBIO11 and pBIO21 with Tn5lac}

Approximately 400 derivatives of $E$. coli $\mathrm{C} 2110$ containing $\mathrm{pBIO} 11$ or $\mathrm{pBIO} 21$ with Tn5lac insertions were used as donors in crosses with wild-type $A$. radiobacter or appropriate exo mutants as recipients. Following transfer into the wild-type, attempts were made to introduce the $\mathrm{Tn} 5$ lac into the corresponding position in the genome by introducing the PI group plasmid pPHIJI and screening for derivatives that were $\mathrm{Kan}^{\mathrm{r}}\left(\mathrm{Tn} 5\right.$ lac) Gent ${ }^{\mathrm{r}}$ (pPH1JI) and Tet ${ }^{\mathrm{s}}$ (pLAFR1). However, no non-mucoid mutants were found, indicating either that, by chance, none of the insertions were into cloned exo genes, or that there is a problem in marker exchanging in this system. Subsequent observations indicated that the latter was the case.

When mutant derivatives of $\mathrm{pBIO} 11$ and $\mathrm{pBIO} 21$ were introduced into appropriate exo mutants, the following results were obtained. 
(a)

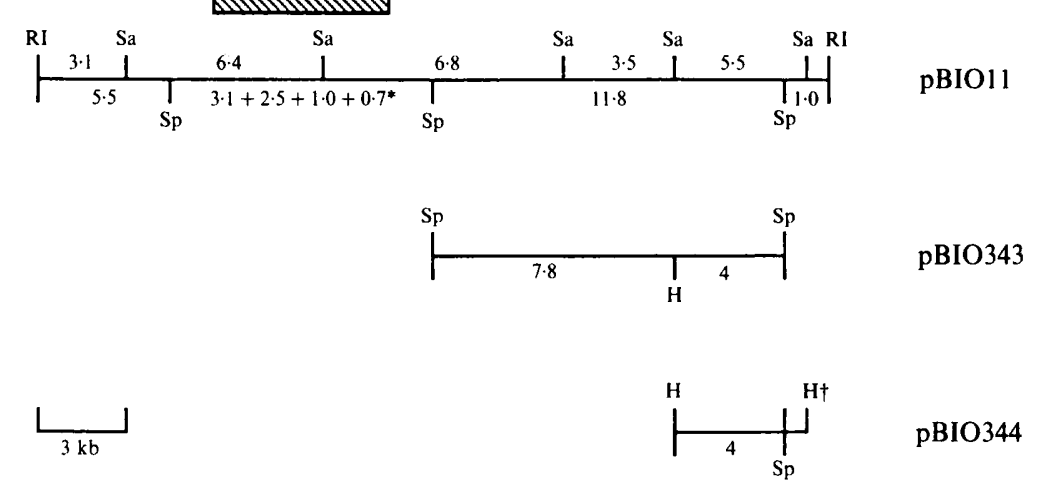

(b)

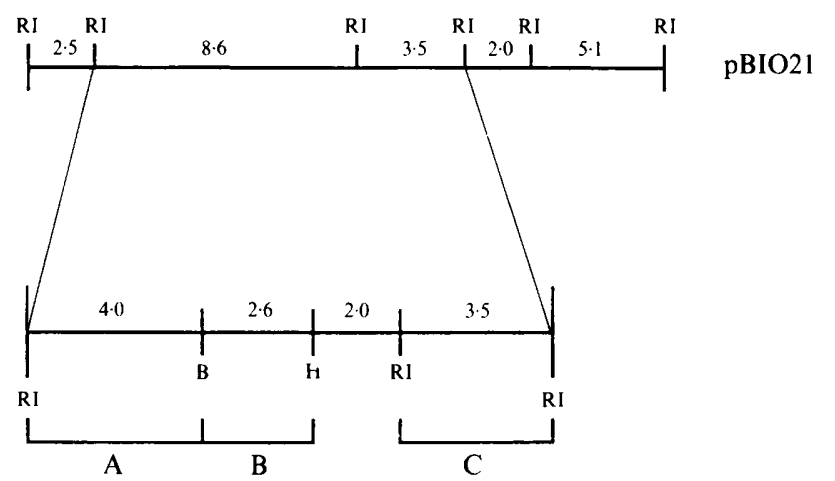

(a) pBIO11. The pBIO11::Tn5lac mutant plasmids were mobilized from derivatives of $E$. coli $\mathrm{C} 2110$ (see Methods) containing the mutant plasmids into strains carrying the exo81, exo82, exo63 and exo53.1 alleles and the transconjugants were plated on MOD-D2 supplemented with glycerol or succinate as appropriate. For 10 of these mutant plasmids, the transconjugants of all four recipients were $\mathrm{Exo}^{-}$(for the recipient with the exo63 allele, the transconjugants with each of these 10 mutant plasmids were non-mucoid on succinate medium but $\mathrm{Exo}^{+}$on glucose medium, just like the mutant strain itself). This observation indicated that the four alleles were in the same complementation group even though they differed in their phenotype.

Plasmid DNA was isolated from the corresponding ten $\mathrm{C} 2110$ (pBIO11::Tn5lac) donor strains and used to transform $E$. coli 803 (it is difficult to isolate sufficient amounts of plasmid DNA from C2110 itself for restriction analysis: unpublished observation). The mutant plasmid DNA was digested with various restriction enzymes; consistent with the sub-cloning experiments (see above) all 10 mutant plasmids contained Tn5lac in the $4.0 \mathrm{~kb}$ HindIII fragment (cloned in pBIO344) that had been shown to correct all four exo mutants. The precise locations of the Tn5lac insertions within this fragment were not determined.
Fig. 2. Localization of exo genes in pBIOI1 and pBIO21. (a) Map of pBIO11 showing EcoRI (RI), SalGI (Sa) and SphI (Sp) sites. Dimensions of the subcloned fragments in pBIO343 and pBIO344 are shown. The box denotes the region in which the 30 'active' phoA insertions were located. For pBIO343, only relevant $\mathrm{HindIII}$ sites $(\mathrm{H})$ are indicated; $\mathrm{H} \dagger$ in pBIO344 represents a HindIII site from the pMP220 polylinker. (b) Map of pBIO21 showing EcoRI (RI) and relevant BamHI (B) and HindIII (H) sites. The $4.0 \mathrm{~kb}$ EcoRI-BamHI fragment which corrects the exo mutants and in which all the exo::TnphoA insertions were located is indicated as fragment $A$. Other phoA insertions which expressed alkaline phosphatase activity but which did not affect EPS production were located in fragments $B$ and $C$.

Having isolated insertional mutations which were clearly in exo genes corresponding to the original exo mutations, these pBIO11 exo::Tn5lac plasmids were transferred to wild type strain T1305 and attempts were made to introduce the Tn 5 lac into the genome by marker exchange. Following introduction of pPH1JI into these derivatives of T1305, several hundreds of Gent ${ }^{r} \mathrm{Kan}^{\mathrm{r}}$ colonies were examined; all were mucoid, indicating that, for some unknown reason, this strain was refractory to the procedure of marker exchange which has been so widely used in genetic studies of other Gram-negative bacteria.

(b) pBIO21. Using the same method as described in the latter part of the above section, $400 \mathrm{pBIO} 21:$ :Tn 5 lac mutant plasmids were transferred from $\mathrm{C} 2110$ into each of the exo mutants that are complemented by pBIO21 itself. None of the transconjugants of any of the mutants was EPS-. It is not clear why such a low proportion of transposon insertions was into exo genes - restriction digests of a random selection of the pBIO21::Tn5lac plasmids showed that they did contain insertions of Tn5lac and that the insertions were in different positions (either in the vector or the cloned DNA). 
Isolation of 'dominant' exo mutations in cloned A. radiobacter DNA following mutagenesis with Tn5lac

Following the mutagenesis of pBIO11 and pBIO21, mutant derivatives containing Tn5lac insertions were transferred into the wild-type strain. With pBIO11, it was found in 10 cases that the transconjugants were nonmucoid. Plasmid DNA was isolated from the corresponding $E$. coli donor strains and restriction mapping revealed that the insertions were close to the previously isolated exo::Tn5lac mutations; i.e. within the $4 \mathrm{~kb}$ fragment that had been cloned in pBIO344.

This observation was reminiscent of those of Gray et al. (1990) and Reed et al. (1991), who identified two genes, exo $X$ and exoY, in Rhizobium sp. NGR 234 and $R$. meliloti, respectively. When these two pairs of genes were both cloned in a recombinant plasmid, such constructs had no obvious effects on EPS production. However, if there was an 'imbalance' in the ratio of exoX to exo $Y$ such that the former was in excess, then the strain would be non-mucoid. Such an 'imbalance' was obtained by cloning exo $X$ separately from exo $Y$ or, more relevant to the observation reported here, by mutagenesis of the plasmid containing both exoX $X$ and exo $Y$ and isolation of insertions into the latter.

It is possible that in pBIO11 there may also be two genes, perhaps similar to exo $X$ and exo $Y$ and that mutations in the latter cause a relative excess of exoX gene product. In order to locate the proposed exoX-like gene in $\mathrm{pBIO} 11$, derivatives of $\mathrm{pBIO} 11$ that contained the 'dominant' exo alleles were re-mutagenized with a derivative of $\operatorname{Tn} 3(\mathrm{Tn} 3 \mathrm{HoHol})$ (Stachel et al., 1985) and these secondarily mutated plasmids were re-introduced into wild-type strain T1305. Some mucoid colonies were identified, consistent with Tn 3 HoHol having inserted into the exoX-like gene. Restriction mapping showed that these $\mathrm{Tn} 3 \mathrm{HoHol}$ insertions were closely linked to the original Tn5lac-induced dominant exo mutations; again they were located in the $4.0 \mathrm{~kb}$ HindIII fragment mentioned above.

It should be noted that when the pBIO11 exo::Tn5lac mutant plasmids which were identified on the basis of their inability to correct the NTG-induced exo mutants were introduced into wild-type strain T1305, the transconjugants were still mucoid showing that these mutations were not dominant.

Following a similar procedure involving the mutagenesis of pBIO21 with Tn5lac no dominant mutations were identified out of 200 tested.

\section{TnphoA mutagenesis of $p B I O 11$ and $p B I O 21$}

As described in the Introduction, the use of translational fusions between a 'target' gene and a defective phoA gene, lacking the signal sequence, has been of value for deducing if the product of the target gene is located in the bacterial membranes or the periplasm. Indeed, Long et al. (1988a) thus showed that products of several exo genes had such a subcellular location. To test if any of the products of the genes (and, in particular, exo genes) in $\mathrm{pBIO11}$ or $\mathrm{pBIO} 21$ were also at or near the cell surface, they were each mutagenized with TnphoA (see Methods). For each mutagenesis, approximately 5000 transconjugants were plated on complete medium supplemented with XP, a chromogenic indicator for alkaline phosphatase. Approximately $1 \%$ of the colonies were bluer than the background colour. Plasmid DNA was isolated from these and introduced into $E$. coli by transformation and these mutant plasmids were then re-introduced into both wild-type and appropriate exo mutant strains of $A$. radiobacter.

With pBIO11, 30 'active' insertions of TnphoA expressed alkaline phosphatase activity in Rhizobium. Each of these mutant plasmids also conferred enzymic activity when transferred to $A$. radiobacter. When mobilized into each of the exo mutants that are corrected by pBIO11, all of the 'active' TnphoA insertions restored them to an $\mathrm{EPS}^{+}$phenotype, showing that the mutations were not in the exo loci defined by exo81, exo82, exo63 and exo51.1. These TnphoA insertions were mapped and were found to be located in a cluster in the cloned DNA in pBIO11 approximately $12 \mathrm{~kb}$ from the exo loci that had been identified earlier (Fig. 2a). It remains to be determined if these phoA fusions are in other exo genes, which are in a different complementation group.

Following TnphoA mutagenesis of pBIO21, 22 alkaline-phosphatase-positive derivatives of $R$. leguminosarum were obtained. Each of these mutant plasmids was shuttled through $E$. coli and then into wild-type $A$. radiobacter; in all cases the $A$. radiobacter transconjugants were blue on media containing XP. Initially the mutant plasmids were introduced into the $\mathrm{Exo}^{-}$strains containing the unusual (because they were also corrected by pBIO11) alleles exo81 and exo82. It was found that 12 of the 'active' mutant plasmids no longer corrected the Exo $^{-}$defect of these strains. All 12 such insertions were in the same $4 \mathrm{~kb} E c o \mathrm{RI}-$ Bam HI fragment that had been shown to correct all the exo alleles that were corrected by pBIO21 itself (region A in Fig. 2b). In all the other mutant plasmids which contained alkaline-phosphatasepositive insertions, the transposon was located close to, but not in the $4.0 \mathrm{~kb}$ EcoRI-BamHI fragment (regions B and $\mathrm{C}$ in Fig. $2 b$ ). Complementation tests between the exo mutant $\mathrm{AP}^{+}$plasmids and the other, original exo mutants were also attempted but the results were not readily interpretable (not shown). The arrangement of genes and complementation groups within the exo region will be precisely determined when the sequence of this region of pBIO21 and the exact location of the TN5phoA insertions are established. 
Correction of one exo mutant of $A$. radiobacter by cloned exoB from $R$. meliloti

The succinoglycan of $R$. meliloti strain 1021 is similar if not identical in structure to that of $A$. radiobacter strain NCIB 11883. To test if the exo genes of the former could complement any of the exo mutants that we had isolated, four different plasmids containing defined exo loci of $R$. meliloti were introduced into each of the exo mutants of A. radiobacter.

Plasmids pD34 (containing exoP, $N, M, A, L, K, H$ ) and $\mathrm{pD} 15$ (exo $C)$ corrected none of the $A$. radiobacter mutants but pD56 restored EPS production to one mutant, SGN-1, which had been induced by $\operatorname{Tn} 5$ mutagenesis (A. Cornish, personal communication). Plasmid pD56 contains the cloned exoJ, $G, F, Q$ and $B$ loci. To determine which of these corresponded to the locus mutated in strain SGN-1, different derivatives of pD56 with $\operatorname{Tn} 5$ in each of these loci were transferred to $\mathrm{SGN}-1$. It was found that the mutant derivative with $\operatorname{Tn} 5$ in $e x o B$ was completely non-mucoid. Further, plasmid pEX312, which contains exoP, $N, M, A, L, K, H, J, G, F$ and $Q$, but not exoB, also failed to correct the EPS ${ }^{-}$ defect of $\mathrm{SGN}-1$. It has recently been shown that the exoB locus encodes a UDP-galactose 4-epimerase (Buendia et al., 1991).

Given the similarity in the EPSs of the two genera, we were surprised that so few of the exo mutants of $A$. radiobacter were corrected by exo loci of $R$. meliloti. In contrast, in similar experiments, Cangelosi et al. (1988) found that the majority of the exo mutants in a strain of $A$. tumefaciens were restored by one of the exo loci of $R$. meliloti.

In addition to the cloned exo genes of $R$. meliloti, plasmids pIJ3040 (Borthakur et al., 1986) and pI10, which contain undefined exo genes required for the production of the xanthan polysaccharide of the phytophathogen Xanthomonas campestris, were mobilized into the exo mutants of $A$. radiobacter. None of the mutants was complemented. Further, plasmid pIJ1427 (Borthakur et al., 1986) and seven cosmids containing cloned exo genes (Diebold \& Noel, 1989) of $R$. leguminosarum were transferred to the Agrobacterium mutants; again none was restored to an $\mathrm{EPS}^{+}$phenotype.

\section{Discussion}

In this paper we have described the isolation of mutants of a strain of $A$. radiobacter which are defective in the synthesis of the succinoglycan EPS and have initiated the characterization of the corresponding cloned DNA. A number of features have emerged from this work.

Firstly, it is clear that the exo genes are quite widely dispersed in this strain. We have identified five non- overlapping groups of plasmids or 'contigs,' and we have isolated several other exo mutants which are corrected by none of the plasmids in these five groups. This dispersal of exo genes is in contrast to the situation in $R$. meliloti, where, apart from exoC and exoD, the known exo 'structural' genes are clustered on a large plasmid (Long et al., 1988b; Finan et al., 1986). Although not stated explicitly, examination of the results of Cangelosi et al. (1987) suggests that in $A$. tumefaciens the exo genes are also more scattered than in $R$. meliloti.

Several phenotypically distinct classes of exo mutants were isolated. These ranged from those that appeared to be completely non-mucoid to those which made reduced amounts of the polymer to some in which the colonies had a rough appearance. Of particular interest were those which had a wild-type morphology on media containing glucose or glycerol as sole $\mathrm{C}$ source but which were EPS $^{-}$on succinate- or fumarate-containing media. This difference was not due to the effects of $\mathrm{pH}$ on EPS production and at present its biochemical basis is not known. It is obvious that these mutants are not grossly defective in succinate uptake and/or utilization since they appear to grow perfectly well with succinate as the sole $\mathrm{C}$ source. Interestingly, these $\mathrm{C}$-source-conditional alleles are closely linked to mutations that block EPS production irrespective of the $\mathrm{C}$-source, since some of the 'group 2' plasmids and pBIO11 correct representatives of both classes of mutant.

It was striking that several exo mutants could be corrected by different cloned fragments of DNA that shared no detectable homology. We have no clear answer to this apparent paradox, but two testable models are presented here. One is that, like $R$. meliloti (Glazebrook $\&$ Walker, 1989), A. radiobacter has the potential to make two types of EPS molecule but that normally the synthesis of one of these is suppressed. However, by cloning the 'silent' exo genes, their expression may become constitutive (due, for example, to the activity of a vector promoter) and the 'second' EPS would be made. Thus, correction of these mutants by the group 2 plasmids would be by the restoration of the genuinely corresponding wild-type DNA but correction by $\mathrm{pB} 1 \mathrm{O} 11$ would be due to the deregulated synthesis of the 'new' EPS (or vice versa). A second hypothetical model invokes a regulatory system. If the mutants that were corrected by both classes of plasmid were in a gene whose function were to activate expression of other 'structural' exo genes, then such mutants might be corrected either by introducing the corresponding DNA or by cloning the 'structural' exo genes such that they were expressed from a vector promoter and so are independent of the normal regulatory control.

Another unexplained phenomenon concerns the difficulty encounted in marker exchanging transposons from 
a recombinant plasmid to the corresponding location in the genome. It may simply be that this strain of $A$. radiobacter has a much lower efficiency of recombination than (for example) Rhizobium. Whatever the reason, this deficiency, unless overcome, will hamper future genetic analysis in this system.

Sequence analysis initially indicated that at least some exo genes encoded proteins that were located in the bacterial membrane, since some had extremely hydrophobic regions (Borthakur et al., 1988; Gray \& Rolfe, 1990). This was confirmed by the use of phoA fusions into exo genes, several of which expressed alkaline phosphatase activity in $R$. meliloti and $R$. leguminosarum (Long $e t$ al., 1988a; Latchford et al., 1991).

Following mutagenesis of pBIO21 with TnphoA, several 'active' insertions were identified which were found to be in exo genes since they abolished the ability of pBIO21 to complement one or more exo mutants. In contrast, the insertions of TnphoA into pBIO11 which expressed alkaline phosphatase were not in the previously identified exo DNA but were $12 \mathrm{~kb}$ from it. These mutations were not marker-exchanged so it is not possible to say if they are in another, linked, exo locus on pBIO11.

The first demonstration that EPS production could be inhibited by the presence of multiple copies of a gene came from the work of Borthakur et al. (1985) and Borthakur \& Johnston (1987). In $R$. leguminosarum biovar phaseoli, there is a gene termed psi, on the Sym plasmid, close to other nodulation and nitrogen-fixation genes. When psi is cloned, it inhibits EPS synthesis but this can be counteracted by the introduction of a cloned pss $A$ (exo) gene which is required for EPS production (Borthakur \& Johnston 1987). Thus the inhibitory effects of the excess of the psi product can be overcome by a corresponding increase in the levels of the pss product. Strikingly, as judged by sequence analysis and the use of pho $A$ fusions, the products of both psi and pss $A$ are located in the membrane, suggesting that there may be some post-translational interaction between them (Borthakur \& Johnston, 1987; Latchford et al., 1991).

A similar situation appears to exist in other rhizobial strains. Two genes, exoX and exo $Y$, have been identified in Rhizobium sp. NGR234 and in R. meliloti which share some homology in their sequences and have similarities in their function relative to psi and pss $A$, respectively (Gray et al., 1990; Zhan \& Leigh, 1990). However, in these two strains exo $X$ and exo $Y$ are adjacent to each other whereas psi and pss $A$ are not only unlinked, but are on different replicons. When exo $X$ and exo $Y$ are cloned on the same recombinant plasmid, mutations in the latter cause a relative excess of exoX gene product and hence result in a reduction of EPS production (Reed $e t$ al., 1991; Gray et al., 1990). A similar case seems to apply to some exo genes of $A$. radiobacter cloned in pBIO11 since certain insertions, close to mutations that abolish EPS synthesis, result in a non-mucoid phenotype when the mutant plasmids are transferred to the wild-type strain of $A$. radiobacter. It will be of interest to see if pBIO11 contains genes equivalent to exo $X$ and exo $Y$ or whether we have identified a different 'two-component' system.

Whereas Cangelosi et al. (1987) found that most of the exo mutants of $\boldsymbol{A}$. tumefaciens could be corrected by the introduction of one of the cloned exo genes of $R$. meliloti, we found that only one out of 44 of the exo mutants that we had isolated in $A$. radiobacter was restored by an $R$. meliloti exo gene. This mutant, SGN-1, was corrected by the $R$. meliloti exoB gene, which has recently been shown to encode a UDP-galactose 4-epimerase (Buendia et al., 1991). In view of the similarities of the succinoglycan EPS molecules of $R$. meliloti and of $A$. radiobacter it seems surprising that such a low proportion of the exo mutants in the latter have functional equivalents in the former. Given the relatively close taxonomic relatedness of Agrobacterium and R. meliloti, it is unlikely that this failure of intergeneric complementation is due to an inability of the $R$. meliloti genes to be expressed in Agrobacterium; in fact, using exo::phoA fusions, it was found that intergeneric expression of these fusions occurred (unpublished observations). Again, it seems inherently unlikely that a very similar EPS polymer would be made by different biochemical routes.

This work was funded by Shell Research Ltd. We are grateful to Allan Downie for useful discussions, to Graham Walker, Mike Daniels and Dale Noel for generously supplying strains and plasmids, and to Alan Cavill for technical assistance.

\section{References}

BERINGER, J. E. (1974). R factor transfer in Rhizobium leguminosarum. Journal of General Microbiology 84, 188-198.

Beringer, J. E., Beynon, J. L., Buchanan-Wollaston, A. V. \& Johnston, A. W. B. (1978). Transfer of the drug-resistance transposon Tn5 to Rhizobium. Nature, London 276, 633-634.

BORTHAKUR, D. \& JohNSTON, A. W. B. (1987). Sequence of psi, a gene on the symbiotic plasmid which inhibits exopolysaccharide production and nodulation and demonstration that its transcription is inhibited by $p s r$, another gene on the symbiotic plasmid. Molecular and General Genetics 207, 149-154.

BorthakuR, D., Downie, J. A., Johnston, A. W. B. \& Lamb, J. W. (1985). psi, a plasmid-linked Rhizobium phaseoli gene which inhibits exopolysaccharide production and is required for symbiotic nitrogen fixation. Molecular and General Genetics 200, 278-282.

Borthakur, D., Barber, C. E., Lamb, J. W., Daniels, M. J., Downie, J. A. \& Johnston, A. W. B. (1986). A mutation that blocks exopolysaccharide synthesis prevents nodulation of peas by Rhizobium leguminosarum but not of beans by $R$. phaseoli and is corrected by cloned DNA from Rhizobium or the phytopathogen Xanthomonas. Molecular and General Genetics 203, 320-323.

Borthakur, D., Barker, R. F., LATChFord, J. W., Rossen, L. \& Johnston, A. W. B. (1988). Analysis of pss genes of Rhizobium leguminosarum required for exopolysaccharide synthesis and nodulation of peas: their primary structure and their interaction with psi and other nodulation genes. Molecular and General Genetics 213, 155162. 
Buendia, A. N., Enekel, B., Koplin, R., Niehaus, K., Arnold, W. \& PUHLER, A. (1991). The Rhizobium meliloti exoZ/exoB fragment of megaplasmid 2: exoB functions as an UDP-galactose 4-epimerase and exoZ shows homology to nodX of Rhizobium leguminosarum bv. viciae strain TOM. Journal of Bacteriology (in the Press).

Cangelosi, G. A., Hung, L., Puvanesarajah, V., Stacey, G., Ozga, D. A., Leigh, J. A. \& NesteR, E. W. (1987). Common loci for Agrobacterium tumefaciens and Rhizobium meliloti exopolysaccharide synthesis and their roles in plant interactions. Journal of Bacteriology 169, 2086-2091.

DIEBOLD, R. \& NOEL, K. D. (1989). Rhizobium leguminosarum exopolysaccharide mutants: biochemical and genetic analysis and symbiotic behaviour on three hosts. Journal of Bacteriology 171, 4821-4830.

DoherTy, D., Leigh, J. A., GlazebrooK, J. \& Walker, G. C. (1988). Rhizobium meliloti mutants that overproduce the $R$. meliloti acidic calcofluor-binding exopolysaccharide. Journal of Bacteriology 170, 4249-4256.

Downie, J. A., Hombrecher, G., MA, Q.-S., KNIGHT, C. D., Wells, B. \& Johnston, A. W. B. (1983). Cloned nodulation genes of Rhizobium leguminosarum determine host-range specificity. Molecular and General Genetics 190, 359-365.

Dylan, T., Ielpi, L., Stanfield, S., Kashyap, L., Douglas, C. J., YANOFSKy, M., Nester, E. W., HelinsKI, D. R. \& DitTA, G. (1986). Rhizobium meliloti genes required for nodule development are related to chromosomal virulence genes in Agrobacterium tumefaciens. Proceedings of the National Academy of Sciences of the United States of America 83, 4403-4407.

FIGURSKI, D. H. \& HelinSKI, P. R. (1979). Replication of an origincontaining derivative of plasmid RK2 dependent on a plasmid function provided in trans. Proceedings of the National Academy of Sciences of the United States of America 76, 1648-1652.

Finan, T. M., KunKel, B., De Vos, G. F. \& Signer, E. R. (1986). Second symbiotic megaplasmid in Rhizobium meliloti carrying exopolysaccharide and thiamine synthesis genes. Journal of Bacteriology 167, 66-72.

Friedman, A. M., Long, S. R., Brown, S. E., Buikema, W. J. \& AUSUBEL, F. M. (1982). Construction of the broad host range cosmid cloning vector and its use in the genetic analysis of Rhizobium mutants. Gene 18, 289-296.

Geremia, R. A., Cavaignac, S. Zomeguitta, A., Toro, N., Olivares, J. \& UGALDE, R. A. (1987). A Rhizobium meliloti mutant that forms ineffective pseudonodules in alfalfa produces exopolysaccharide but fails to form $\beta-(1 \rightarrow 2)$ glucan. Journal of Bacteriology 169, 880-884.

GlazebrooK, J. \& WaLKeR, G. C. (1989). A novel exopolysaccharide can function in place of the calcofluor-binding exopolysaccharide in nodulation of alfalfa by Rhizobium meliloti. Cell 56, 661-672.

GRAY, J. X. \& RolfE, B. G. (1990). Exopolysaccharide production in Rhizobium and its role in invasion. Molecular Microbiology 4, 14251431.

Gray, J. X., DJordjeVic, N. A. \& RolFe, B. G. (1990). Two genes that regulate exopolysaccharide production in Rhizobium sp. strain NGR234: DNA sequences and resultant phenotypes. Journal of Bacteriology 172, 193-203.

Grosveld, F. G., Dahr, H-H. M., De Boer, E. \& Flavell, R. A. (1981). Isolation of $\beta$-globulin-related genes from a human cosmid library. Gene 13, 227-237.

Hisamatsu, M., Abe, J., Amemura, A. \& Harada, T. (1980). Structural elucidation of succinoglycan and related polysaccharides from Agrobacterium and Rhizobium by fragmentation with two special glycanases and methylation analysis. Agricultural and Biological Chemistry 44, 1049-1055.

Holmes, D. S. \& QUIGLEY, M. (1981). A rapid boiling method for the preparation of bacterial plasmids. Annals of Biochemistry 114, 193197.

Hombrecher, G., GotZ, R., DibB, N. J., DOWNIE, J. A., Johnston,
A. W. B. \& BRewIN, N. J. (1984). Cloning and mutagenesis of nodulation genes from Rhizobium leguminosarum TOM, a strain with extended host range. Molecular and General Genetics 184, 293-298.

LAMB, J. W., Hombrecher, G. \& JoHnSTON, A. W. B. (1982). Plasmiddetermined nodulation and nitrogen-fixation abilities in Rhizobium phaseoli. Molecular and General Genetics 186, 449-452.

LATCHFORD, J. W., BORTHAKUR, D. \& JOHNSTON, A. W. B. (1991). The products of Rhizobium genes, psi and pss, which affect exopolysaccharide, are associated with the bacterial cell surface. Molecular Microbiology (in the Press).

LeIGH, J. A., SigneR, E. R. \& WALKeR, G. C. (1986). Exopolysaccharide-deficient mutants of Rhizobium meliloti that form ineffective nodules. Proceedings of the National Academy of Sciences of the United States of America 82, 6231-6235.

Linton, J. D., WoODWARD, S. \& GouldneY, D. G. (1987). The consequence of stimulating glucose dehydrogenase activity by the addition of PQQ on metabolite production by Agrobacterium radiobacter NCIB 11883. Applied Microbiology and Biotechnology 25, 357-361.

LONG, S., McCune, S. \& Walker, G. C. (1988a). Symbiotic loci of Rhizobium meliloti identified by random TnphoA mutagenesis. Journal of Bacteriology 170, 4257-4265.

Long, S., Reed, J. W., Himawan, J. \& Walker, G. C. (1988b) Genetic analysis of a cluster of genes required for synthesis of the calcofluor-binding exopolysaccharide of Rhizobium meliloti. Journal of Bacteriology 170, 4239-4248.

Maniatis, T., Fritsch, E. F. \& SAmbrooK, J. (1982). Molecular Cloning: a Laboratory Manual. Cold Spring Harbor, NY: Cold Spring Harbor Laboratory.

MANoIL, C. \& BeckwITH, J. (1985). TnphoA: a transposon probe for protein export signals. Proceedings of the National Academy of Sciences of the United States of America 82, 8129-8137.

REED, J. W., CAPAGE, M.\& WALKER, G. C. (1991). Rhizobium meliloti exoG and exoJ affect the exoX/exoY system for regulation of exopolysaccharide production. Journal of Bacteriology 173, 37763788.

Ruvxun, G. B. \& Ausubel, F. M. (1981). A general method for sitedirected mutagenesis in procaryotes. Nature, London 289, 85-88.

Simon, R., QUANDT, J. \& KLIPP, W. (1989). New derivatives of transposon $\mathrm{Tn} 5$ suitable for mobilisation of replicons, generation of operon fusions and induction of genes in Gram-negative bacteria. Gene 80, 161-169.

SOUTHERN, E. M. (1975). Detection of specific sequences among DNA fragments separated by gel electrophoresis. Journal of Molecular Biology 98, 503-517.

Spaink, H. P., Orken, R. J. H., Wijffelman, C. A., Pees, E. \& LUGTENBERG, B. J. J. (1987). Promoters in the nodulation region of the Rhizobium leguminosarum Sym plasmid pRL1JI. Plant Molecular Biology 9, 27-39.

Stachel, S. E., AN, G., Flores, C. \& Nester, E. W. (1985). A Tn3 lac $Z$ transposon for the random generation of $\beta$-galactosidase gene fusions; application to the analysis of gene expression in Agrobacterium. EMBO Journal 4, 891-898.

SUTHERLAND, I. W. (1985). Biosynthesis and composition of gramnegative bacterial extracellular and wall polysaccharides. Annual Review of Microbiology 39, 243-270.

Uttaro, A. D., Cangelosi, G. A., Geremia, R. A., Nester, E. W. \& UGALDE, R. A. (1990). Biochemical characterisation of avirulent exoC mutants of Agrobacterium tumefaciens. Journal of Bacteriology 172, 1640-1646.

WOOD, W. B. (1966). Host specificity of DNA produced by Escherichia coli; bacterial mutations affecting the restriction and modification of DNA. Journal of Molecular Biology 16, 118-133.

ZhAN, H. \& LeIGH, J. A. (1990). Two genes that regulate exopolysaccharide production in Rhizobium meliloti. Journal of Bacteriology 172, 5254-5259. 